\title{
Predictors of treatment outcomes among patients with multidrug-resistant tuberculosis in Vietnam: a retrospective cohort study
}

\author{
Ian Wrohan 1,2* Thu Anh Nguyen ${ }^{1,3}$, Viet Nhung Nguyen ${ }^{4}$, Binh Hoa Nguyen ${ }^{4}$, Thi Thanh Thuy Hoang ${ }^{4}$,
} Phuong Chi Nguyen ${ }^{3}$, Kavindhran Velen ${ }^{1,2}$, Guy Barrington Marks ${ }^{2,5}$ and Greg James Fox ${ }^{1,2}$

\begin{abstract}
Background: Improving treatment outcomes for multidrug-resistant tuberculosis (MDR-TB) is a leading priority for global TB control. This retrospective cohort study evaluated the factors associated with treatment success among patients treated for MDR-TB in two provinces in Vietnam.

Methods: Treatment outcomes were evaluated for adult patients treated in Hanoi and Thanh Hoa provinces between 2014 and 2016. The primary outcome was the proportion of patients with treatment success, defined as cure or treatment completion. Logistic regression analysis was used to evaluate the relationship between patient clinical and microbiological characteristics and treatment success.

Results: Treatment outcomes were reported in 612 of 662 patients; of these, 401 (65.5)\% were successfully treated. The odds of treatment success were lower for male patients (aOR 0.56,95\% Cl 0.34-0.90), for people living with HIV (aOR 0.44, 95\% Cl 0.20-1.00), and for patients treated for extensive antibiotic resistance (pre-XDR-/XDT-TB) (aOR 0.53, $95 \% \mathrm{Cl}$ 0.29-0.97), compared with others. Patients who achieved culture conversion in the first 4 months of treatment had increased odds (aOR 2.93,95\% Cl 1.33-6.45) of treatment success. In addition, loss to follow-up was less common among patients covered by social health insurance compared to those who paid for treatment out-of-pocket (aOR $0.55,95 \% \mathrm{Cl} 0.32-0.95)$.

Conclusions: Among patients with MDR-TB, males, people living with HIV, and those with more extensive antibiotic resistance at diagnosis are at greatest risk of an unsuccessful treatment outcome. Efforts to optimise the management of co-morbidities (such as HIV), ensure rapid bacteriological conversion, and provide financial support for patients promise to improve treatment outcomes.
\end{abstract}

Keywords: MDR-TB, Gender, HIV, Co-morbidities, Bacteriological conversion

*Correspondence: iwrohan@gmail.com

${ }^{1}$ The Central Clinical School, Faculty of Medicine and Health, The

University of Sydney, 90-92 Parramatta Road, Sydney, NSW 2006, Australia

Full list of author information is available at the end of the article

\section{Background}

Tuberculosis (TB) is the tenth leading cause of death worldwide. An estimated two billion people have been infected with $M$. tuberculosis, and of the 10 million people diagnosed with TB in 2019, 465,000 had rifampicinresistant (RR-TB) or multidrug-resistant (MDR-TB) forms of the disease [1]. The treatment of drug-resistant 
tuberculosis is a prolonged and expensive process, further complicated by the occurrence of side effects resulting from the use of toxic drugs [2]. MDR-TB has a treatment success rate of only $58 \%$, globally [1]. Consequently, drug-resistant TB represents a significant obstacle to realising the WHO End TB Strategy [3]. Vietnam ranks 11th among the top 20 high burden countries for MDR-TB, with 8400 new cases reported in 2019 [1]. In 2009, the Government of Vietnam initiated the Programmatic Management of Drug-resistant Tuberculosis (PMDT) to enhance diagnostic and treatment services for MDR-TB, and to provide free treatment with qualityassured drugs to patients across the country [4]. However despite this, less than $70 \%$ of patients enrolled in MDR-TB treatment achieve a successful outcome [1]. Re-treatment is a costly and time-consuming process, placing a strain on the healthcare system and often burdening families with catastrophic costs associated with treatment, despite government support [5]. Furthermore, re-treatment of TB has an even lower success rate than treatment among those receiving it for the first time [1, 6]. The aim of this study is to evaluate the factors associated with treatment success amongst patients treated for MDR-TB by the National Tuberculosis Programme (NTP) in two provinces of Vietnam. The findings of this study will inform the strengthening of programmatic management of drug-resistant TB in Vietnam.

\section{Methods}

\section{Study setting}

Vietnam is a Southeast Asian country with a population of 96 million people and a high annual TB incidence (176 cases of TB per 100,000 population). It is ranked among the high-burden countries for drug-resistant TB, with 8.8 cases of RR-/MDR-TB per 100,000 population. The Vietnamese healthcare system has four levels of care for managing MDR-TB patients (in descending order): Central, Provincial, District, and Commune. This study was conducted in two of Vietnam's 63 provinces: Hanoi and Thanh Hoa, and included patients with confirmed RR-/MDR-TB who were treated at Provincial and District healthcare facilities within the Vietnamese PMDT program.

\section{Description of programmatic management of patients}

At the time of this study, patients with presumptive MDR-TB were identified from among those presenting for the treatment of $\mathrm{TB}$ with risk factors for drugresistance, including a history of prior treatment for TB, HIV infection, and exposure to individuals with known drug-resistant TB. Rifampicin resistance was confirmed using GeneXpert MTB/RIF and additional drug resistance was assessed using Genotype MTBDRplus and drug-susceptibility testing (DST). Once diagnosed, patients were treated at a provincial inpatient facility for up to 8 weeks and subsequent outpatient care was administered through district health centres. Standardised treatment for MDR-TB was delivered in accordance with WHO guidelines [4, 7]. During this study, 20-month standard and 9-month short-course regimens were used routinely to treat MDR-TB, although individualized regimens were used occasionally for patients with more extensive drug resistance (such as resistance to fluoroquinolones and second-line injectable drugs). Patients were requested to return to the provincial hospital for a monthly clinical evaluation, which included a chest radiograph along with sputum smear and culture analysis. Although most clinical costs were covered by the NTP, other expenses (e.g., transportation) were either selffunded or funded through the social health insurance (SHI) program, which covered at least $80 \%$ of a patient's direct expenses [5].

\section{Study design and participants}

Participants in this retrospective cohort study included consecutive adult (at least 15 years of age) patients who were diagnosed with either RR-TB or MDR-TB and registered for treatment in the PMDT program between January 01, 2014 and December 31, 2016. MDR-TB was defined as patients shown to be resistant to both isoniazid and rifampicin. This group also included patients with more extensive drug resistance, including extensively drug-resistant tuberculosis (XDR-TB) (additional resistance to both a fluoroquinolone and at least one injectable agent) and pre-XDR-TB (additional resistance to either a fluoroquinolone or injectable) [7]. Although study participants need not have been residents of either Hanoi or Thanh Hoa, they were required to have started treatment in one of these provinces.

\section{Data collection}

Patient data were extracted from NTP patient registers, individual clinical records, and the Vietnam electronic TB database (eTB Manager). Ten percent of register entries and patient records were selected, at random, for duplicate data transcription in order to verify the accuracy of data entry. Source documents were transcribed into electronic case report forms developed using Epidata 4.4 (see Additional file 2). Data from multiple sources were linked based upon the following patient identifiers: name, age, gender, address, and treatment dates. Data collected from the source documents included patient demographics, pre-treatment information, treatment details (e.g., sputum smear and mycobacterial culture results), and treatment outcomes (see Additional file 1: Table S1). Treatment outcomes were assigned using standardised 
definitions [4, 7]: success, failure, loss to follow-up, death, or not evaluated (see Additional file 1: Table S2).

\section{Data analysis}

Participant characteristics were evaluated using descriptive statistics. Logistic regression analysis was used to determine the associations between independent variables and treatment outcomes. Univariate analyses were first used to calculate crude (unadjusted) odds ratios (cOR) with a 95\% confidence interval for each variable, and those variables individually associated with treatment success at a level of $p \leq 0.20$ were then evaluated together in a multivariable logistic regression. Multiple imputation was used to address missing values in the dataset, based upon 50 imputations using the fully conditional specification method, with all 23 variables included in the univariate analyses used as predictors. Adjusted odds ratios (aOR) with a 95\% confidence interval were calculated for each variable in the multivariable analysis, and those variables significantly $(p \leq 0.05)$ associated with treatment success were included in the final model. Multicollinearity between variables was evaluated using the variance inflation factor (VIF). Univariate analyses were also performed for treatment failure, loss to followup, and death. However, as the primary outcome of interest was treatment success, multivariable analyses were not performed for the unsuccessful outcomes. Participants for whom a treatment outcome was not evaluated (i.e., not reported), including patients who were transferred to another treatment unit, were not included in the primary analysis. However, to assess the range of impacts that these missing treatment outcomes may have had on the findings of this study, the upper and lower bounds of the estimated treatment success rate were calculated by assuming individuals without an evaluated outcome all had successful outcomes, or all had unsuccessful outcomes. All analyses and operations were done using IBM SPSS version 26 (IBM Corporation, NY).

\section{Ethical considerations}

Ethical approval for the project was obtained though the Human Research Ethics Committee (HREC) at the University of Sydney in Australia (project no. 2018/746), and the Vietnam National Lung Hospital. Due to the retrospective nature of this study, the need for written informed consent was waived by the HREC at the University of Sydney, and consent to access and analyze the patient treatment data used in this study was obtained through the Vietnam National Lung Hospital. All patient data was stored in a secure database during data collection and de-identified prior to analysis to ensure the confidentiality of study participants. All methods were carried out in accordance with relevant guidelines and regulations.

\section{Results}

\section{Participant characteristics}

Treatment records for 662 individual patients with RR-/MDR-TB were retrieved and included in the study (Table 1). The 494 patients who were treated in Hanoi accounted for majority of the study population. Males comprised $76.4 \%$ of the population. Age ranged from 15 to 85 years with a median age of 43 years [interquartile range (IQR) 32-55]. Previous treatment for TB was reported in $532(82.7 \%)$ of the 643 patients for whom data was available. Of the 458 patients who reported the method by which their treatment was financed, 333 $(72.7 \%)$ were supported through social health insurance. Among 527 patients for whom HIV status was recorded, 37 (7.0\%) were HIV-positive. Among 458 patients for whom other co-morbidity data were recorded, the most commonly reported co-morbidities were diabetes (11.4\%) and other respiratory disorders (11.8\%). Among the 645 patients for whom infection site data were recorded, 622 (96.4\%) had pulmonary disease. Although rifampicin resistance was confirmed in all patients using GeneXpert MTB/RIF, additional drug susceptibility test results at the commencement of treatment were available for only 441 of the 662 patients. Among these, 388 (88.0\%) were classified at MDR-TB, $36(8.2 \%)$ as pre-XDR-TB, and 17 $(3.8 \%)$ as XDR-TB.

\section{Treatment outcomes and adverse events}

The median duration of inpatient stay was 28 days (IQR 16-37), and the median total treatment duration was 19 months (IQR 9.7-20.0) (Table 2). Sputum smear conversion within 2 months of starting treatment was observed in $503(85.8 \%)$ of the 586 patients for whom smear results were available, and within 4 months in 519 (96.6\%) of 537 patients. Culture conversion within 2 months of starting treatment was observed in 415 (75.0\%) of the 553 patients for whom mycobacterial culture results were available, and within 4 months in 488 (92.4\%) of 528 patients. Of the 452 patients for whom side effects during inpatient treatment were documented, 39 (8.6\%) experienced one or more side effects. Of the 572 patients for whom side effects during outpatient treatment were recorded, 107 (18.7\%) experienced one or more side effects. Common reported side effects included high uric acid levels (17.0\%), hepatotoxicity (14.2\%), and joint pain (14.2\%).

Treatment success was reported in 401 (65.5\%) of the 612 patients for whom treatment outcome was evaluated (Table 3). Of these, $96.0 \%$ were cured and $4.0 \%$ completed treatment. Of the 211 patients who did not 
Table 1 Patient characteristics

\begin{tabular}{|c|c|c|c|}
\hline & Hanoi province & Thanh Hoa province & Total \\
\hline Total & 494 & 168 & 662 \\
\hline Gender & $n=494$ & $n=168$ & $\mathrm{n}=662$ \\
\hline Male & $365(73.9 \%)$ & $141(83.9 \%)$ & $506(76.4 \%)$ \\
\hline Female & $129(26.1 \%)$ & $27(16.1 \%)$ & $156(23.6 \%)$ \\
\hline Age (years) & $\mathrm{n}=494$ & $n=167$ & $n=661$ \\
\hline Mean (IQR) & $43.0(32.0-55.0)$ & $44.0(33.0-56.0)$ & $43.0(32.0-55.0)$ \\
\hline \multicolumn{4}{|l|}{ By group (years) } \\
\hline$\leq 19$ & $12(2.4 \%)$ & $1(0.6 \%)$ & $13(2.0 \%)$ \\
\hline $20-39$ & $204(41.3 \%)$ & $64(38.3 \%)$ & $268(40.5 \%)$ \\
\hline $40-59$ & $207(41.9 \%)$ & $71(42.5 \%)$ & $278(42.1 \%)$ \\
\hline $60-79$ & $69(14.0 \%)$ & $29(17.4 \%)$ & $98(14.8 \%)$ \\
\hline$\geq 80$ & $2(0.4 \%)$ & $2(1.2 \%)$ & $4(0.6 \%)$ \\
\hline Not reported & 0 & 1 & 1 \\
\hline Previous TB treatment & $n=478$ & $n=165$ & $n=643$ \\
\hline Yes & $394(82.4 \%)$ & $138(83.6 \%)$ & $532(82.7 \%)$ \\
\hline No & $84(17.6 \%)$ & $27(16.4 \%)$ & $111(17.3 \%)$ \\
\hline Not reported & 16 & 3 & 19 \\
\hline $\begin{array}{l}\text { Financially supported through social health } \\
\text { insurance }\end{array}$ & $\mathrm{n}=\mathbf{3 1 1}$ & $n=147$ & $n=458$ \\
\hline Yes & $224(72.0 \%)$ & $109(74.1 \%)$ & $333(72.7 \%)$ \\
\hline No & $87(28.0 \%)$ & $38(25.9 \%)$ & $125(27.3 \%)$ \\
\hline Not reported & 183 & 21 & 204 \\
\hline HIV status & $n=453$ & $n=74$ & $n=527$ \\
\hline Positive & $32(7.1 \%)$ & $5(6.8 \%)$ & $37(7.0 \%)$ \\
\hline Negative & $421(92.9 \%)$ & 69 (93.2\%) & $490(93.0 \%)$ \\
\hline Not reported & 41 & 94 & 135 \\
\hline Other comorbidities & $\mathrm{n}=\mathbf{3 1 2}$ & $n=146$ & $n=458$ \\
\hline Diabetes & $44(14.1 \%)$ & $8(5.5 \%)$ & $52(11.4 \%)$ \\
\hline Heart disease & $12(3.8 \%)$ & $6(4.1 \%)$ & $18(3.9 \%)$ \\
\hline Liver disease & $13(4.2 \%)$ & $7(4.8 \%)$ & $20(4.4 \%)$ \\
\hline Kidney disease & $2(0.6 \%)$ & $0(0 \%)$ & $2(0.4 \%)$ \\
\hline Malnutrition & $7(2.2 \%)$ & $7(4.8 \%)$ & $14(3.1 \%)$ \\
\hline Psychiatric disorder & $13(4.2 \%)$ & $0(0 \%)$ & $13(2.8 \%)$ \\
\hline Respiratory disorder ${ }^{a}$ & $32(10.3 \%)$ & $22(15.1 \%)$ & $54(11.8 \%)$ \\
\hline Substance abuse & $8(2.6 \%)$ & $10(6.8 \%)$ & $18(3.9 \%)$ \\
\hline Other ${ }^{b}$ & $10(3.2 \%)$ & $3(2.1 \%)$ & $13(2.8 \%)$ \\
\hline Not reported & 182 & 22 & 204 \\
\hline Infection site & $n=481$ & $n=164$ & $n=645$ \\
\hline Pulmonary & $458(95.2 \%)$ & $164(100.0 \%)$ & $622(96.4 \%)$ \\
\hline Extra-pulmonary & $12(2.5 \%)$ & $0(0 \%)$ & $12(1.9 \%)$ \\
\hline Both & $11(2.3 \%)$ & $0(0 \%)$ & $11(1.7 \%)$ \\
\hline Not reported & 13 & 4 & 17 \\
\hline Initial sputum smear grade & $n=474$ & $n=146$ & $n=620$ \\
\hline Negative & $162(34.2 \%)$ & $66(45.2 \%)$ & $228(36.8 \%)$ \\
\hline Scanty & $8(1.7 \%)$ & $6(4.1 \%)$ & $14(2.3 \%)$ \\
\hline $1+$ & $185(39.0 \%)$ & $23(15.8 \%)$ & $208(33.5 \%)$ \\
\hline $2+$ & $54(11.4 \%)$ & $26(17.8 \%)$ & $80(12.9 \%)$ \\
\hline $3+$ & $65(13.7 \%)$ & $25(17.1 \%)$ & $90(14.5 \%)$ \\
\hline Not reported & 20 & 22 & 42 \\
\hline
\end{tabular}


Table 1 (continued)

\begin{tabular}{llll}
\hline & Hanoi province & Thanh Hoa province & Total \\
\hline Antibiotic resistance at enrolment & $\mathbf{n}=\mathbf{3 0 9}$ & $\mathbf{n}=\mathbf{1 3 2}$ & $\mathbf{n}=\mathbf{4 4 1}$ \\
RR-/MDR-TB only & $257(83.2 \%)$ & $131(98.5 \%)$ & $388(88.0 \%)$ \\
Pre-XDR-TB & $35(11.3 \%)$ & $1(1.5 \%)$ & $36(8.2 \%)$ \\
XDR-TB & $17(5.5 \%)$ & $0(0 \%)$ & $17(3.8 \%)$ \\
Not reported & 185 & 36 & 221 \\
\hline
\end{tabular}

Bolded numbers indicate the number of individuals for whom data were available (percentages exclude those for whom data were not reported)

${ }^{a}$ Respiratory disorder refers to either: atelectasis, bronchiectasis, bronchitis, bronchopneumonia, chronic pulmonary disease, lung tumor, pneumonia, pneumothorax, or respiratory failure

${ }^{b}$ Other comorbidity refers to either: adrenal failure, anemia, esophageal cancer, gout, pleural effusion, or seizure

achieve a successful outcome, 54 (8.2\%) experienced treatment failure, 107 (16.2\%) were lost to follow-up, and $50(7.5 \%)$ patients died. Of the $50(7.5 \%)$ patients for whom a final outcome was not available, 31 were transferred to other provinces. Additional file 1 (Tables S6 and S7) shows the characteristics of patients for whom a treatment outcome was 'not evaluated', compared with those for whom a treatment outcome was reported. Assuming that all 50 patients without an evaluated outcome had been successfully treated, the overall proportion of patients with treatment success could be as high as $68.1 \%$. Alternatively, if these patients all had unsuccessful treatment, as few as $60.6 \%$ of patients may have been treated successfully.

\section{Factors associated with treatment success}

Univariate analyses identified 15 variables (Table 4) for which there was some evidence (at the level of $p \leq 0.20$ ) of an association with a successful treatment outcome (cure or treatment completion). Only 230 of 612 cases were complete (containing data for all 15 variables) and multiple imputation was thus used to complete the dataset (see Additional file 3). The pooled value for each variable was derived from 50 imputations.

Four variables were then found to be significantly $(p \leq 0.05)$, independently associated with treatment success in the multivariable analysis (see Additional file 1: Fig. S1). Male patients had lower odds of treatment success (aOR 0.56, 95\% CI 0.34-0.90) compared to female patients, and patients also receiving treatment for HIV (aOR 0.44, 95\% CI 0.20-1.00) had lower odds of treatment success compared to patients who were not also under treatment for HIV (Table 5). Patients treated for extensive antibiotic resistance (pre-XDR-/ XDR-TB vs. other forms of RR-/MDR-TB) were less likely (aOR 0.53, 95\% CI 0.29-0.97) to have a successful treatment outcome compared with RR-/MDR-TB cases. However, achieving bacteriological (culture) conversion in the first 4 months of treatment was associated with increased odds (aOR 2.93, 95\% CI 1.33-6.45) of treatment success. There was no evidence of multicollinearity between variables in the multivariable model.

\section{Discussion}

This retrospective cohort study of 662 patients from two provinces of Vietnam found an overall treatment success rate of $65.5 \%$ and identified several important barriers to successful MDR-TB treatment. While treatment outcomes were influenced by a variety of demographic, financial, and clinical factors, a patient's gender, HIV status, the extent of antibiotic resistance at diagnosis, and whether bacteriological conversion was achieved within 4 months of commencing treatment were most strongly associated with treatment success.

The reduced odds of treatment success among patients living with HIV in this study was comparable to other Vietnamese $[8,9]$ and global [10] estimates. Although the HIV burden in Vietnam is relatively low (compared with other high MDR-TB burden counties [1]), and affordable antiretroviral therapy is readily available [11-13], patients receiving concomitant treatment for $\mathrm{HIV} / \mathrm{TB}$ may be at a greater risk of experiencing drug-related side effects compared with patients who are not being treated for HIV [7]. Patient discomfort resulting from severe side effects or pill burden can increase the chance of voluntary withdrawal from treatment, and this may be reflected in the considerable risk of loss to follow-up associated with patients also under treatment for HIV in this study (see Additional file 1: Table S3). The stigma associated with being under treatment for both infections can also result in social alienation and discrimination, further increasing the risk of voluntary withdrawal from treatment $[6,14]$. Additional care for patients living with HIV, including psychosocial support, is thus essential to ensuring that side effects are effectively managed and treatment adherence is optimal [15]. 
Table 2 Microbiological outcomes and side effects for patients, by province

\begin{tabular}{|c|c|c|c|}
\hline & Hanoi province & Thanh Hoa province & Total \\
\hline Total & $n=494$ & $n=168$ & $n=662$ \\
\hline \multicolumn{4}{|l|}{ Treatment duration [median (IQR)] } \\
\hline Start to completion (months) & $19.0(9.8-20.0)$ & $20.0(9.7-21.3)$ & $19.0(9.7-20.0)$ \\
\hline Inpatient regimen (days) & $25(16-34)$ & $33(19-42)$ & $28(16-37)$ \\
\hline Smear conversion after 2 months & $n=454$ & $n=132$ & $\mathrm{n}=586$ \\
\hline Yes & $418(92.1 \%)$ & $85(64.4 \%)$ & $503(85.8 \%)$ \\
\hline No & $36(7.9 \%)$ & $47(35.6 \%)$ & $83(14.2 \%)$ \\
\hline Not reported & 40 & 36 & 76 \\
\hline Smear conversion after 4 months & $n=421$ & $n=116$ & $\mathrm{n}=537$ \\
\hline Yes & 409 (97.1\%) & $110(94.8 \%)$ & $519(96.6 \%)$ \\
\hline No & $12(2.9 \%)$ & $6(5.2 \%)$ & $18(3.4 \%)$ \\
\hline Not reported & 73 & 52 & 125 \\
\hline Culture conversion after 2 months & $n=448$ & $n=105$ & $n=553$ \\
\hline Yes & $405(90.4 \%)$ & $10(9.5 \%)$ & $415(75.0 \%)$ \\
\hline No & $43(9.6 \%)$ & $95(90.5 \%)$ & $138(25.0 \%)$ \\
\hline Not reported & 46 & 63 & 109 \\
\hline Culture conversion after 4 months & $n=420$ & $n=108$ & $\mathrm{n}=\mathbf{5 2 8}$ \\
\hline Yes & $402(95.7 \%)$ & $86(79.6 \%)$ & $488(92.4 \%)$ \\
\hline No & $18(4.3 \%)$ & $22(20.4 \%)$ & $40(7.6 \%)$ \\
\hline Not reported & 74 & 60 & 134 \\
\hline \multicolumn{4}{|l|}{ Side effects during treatment } \\
\hline At least one inpatient side effect reported & $\mathrm{n}=308$ & $n=144$ & $n=452$ \\
\hline Yes & $23(7.5 \%)$ & $16(11.1 \%)$ & $39(8.6 \%)$ \\
\hline No & $285(92.5 \%)$ & $128(88.9 \%)$ & $413(91.4 \%)$ \\
\hline Not reported & 186 & 24 & 210 \\
\hline At least one outpatient side effect reported & $n=447$ & $n=125$ & $\mathrm{n}=\mathbf{5 7 2}$ \\
\hline Yes & $75(16.8 \%)$ & $32(25.6 \%)$ & $107(18.7 \%)$ \\
\hline No & $372(83.2 \%)$ & $93(74.4 \%)$ & $465(81.3 \%)$ \\
\hline Not reported & 47 & 43 & 90 \\
\hline Outpatient side effects reported ${ }^{a}$ & $\mathrm{n}=195$ & $\mathrm{n}=52$ & $\mathrm{n}=\mathbf{2 4 7}$ \\
\hline Blood disorder & $6(3.1 \%)$ & $0(0 \%)$ & $6(2.4 \%)$ \\
\hline Bowel pain & $3(1.5 \%)$ & $2(3.8 \%)$ & $5(2.0 \%)$ \\
\hline Hearing loss & $9(4.6 \%)$ & $3(5.8 \%)$ & $12(4.9 \%)$ \\
\hline Hepatotoxicity & $35(17.9 \%)$ & $0(0 \%)$ & $35(14.2 \%)$ \\
\hline High blood sugar & $10(5.1 \%)$ & $0(0 \%)$ & $10(4.0 \%)$ \\
\hline High uric acid & $42(21.5 \%)$ & $0(0 \%)$ & $42(17.0 \%)$ \\
\hline Hypokalemia & $15(7.7 \%)$ & $0(0 \%)$ & $15(6.1 \%)$ \\
\hline Joint pain & $19(9.7 \%)$ & $16(30.8 \%)$ & $35(14.2 \%)$ \\
\hline Loss of appetite & $11(5.6 \%)$ & $0(0 \%)$ & $11(4.5 \%)$ \\
\hline Nephrotoxicity & $17(8.7 \%)$ & $0(0 \%)$ & $17(6.9 \%)$ \\
\hline Neurotoxicity & $7(3.6 \%)$ & $1(1.9 \%)$ & $8(3.2 \%)$ \\
\hline Nausea & $0(0 \%)$ & $23(44.2 \%)$ & $23(9.3 \%)$ \\
\hline Vision loss & $7(3.6 \%)$ & $2(3.8 \%)$ & $9(3.6 \%)$ \\
\hline Vertigo & $14(7.2 \%)$ & $5(9.6 \%)$ & 19 (7.7\%) \\
\hline Not reported & 299 & 116 & 415 \\
\hline
\end{tabular}

Bolded numbers indicate the number of individuals for whom data were available (percentages exclude those for whom data were not reported)

a Patients could report more than one side effect 
Table 3 Patient treatment outcomes by province

\begin{tabular}{|c|c|c|c|}
\hline & Hanoi province & Thanh Hoa province & Total \\
\hline Total & $\mathrm{n}=494$ & $n=168$ & $\mathrm{n}=662$ \\
\hline Treatment outcomes & $n=494$ & $n=168$ & $n=662$ \\
\hline Cure & $314(63.6 \%)$ & $71(42.3 \%)$ & 385 (58.2\%) \\
\hline Treatment completion & $12(2.4 \%)$ & $4(2.4 \%)$ & $16(2.4 \%)$ \\
\hline Treatment failure & $43(8.7 \%)$ & $11(6.6 \%)$ & $54(8.2 \%)$ \\
\hline Loss to follow-up & $71(14.4 \%)$ & $36(21.4 \%)$ & $107(16.2 \%)$ \\
\hline Death & $30(6.1 \%)$ & $20(11.9 \%)$ & $50(7.5 \%)$ \\
\hline Not evaluated & $24(4.8 \%)$ & $26(15.5 \%)$ & $50(7.5 \%)$ \\
\hline Transferred out & $10(2.0 \%)$ & $21(12.5 \%)$ & $31(4.7 \%)$ \\
\hline Unknown outcome & $14(2.8 \%)$ & $5(3.0 \%)$ & $19(2.8 \%)$ \\
\hline Treatment success $^{\mathrm{a}}$ & $n=470$ & $n=142$ & $n=612$ \\
\hline Successful outcome (cure or completion) & $326(69.4 \%)$ & $75(52.3 \%)$ & $401(65.5 \%)$ \\
\hline Unsuccessful outcome (failure, loss to follow-up, or death) & $144(30.6 \%)$ & $67(47.7 \%)$ & $211(34.5 \%)$ \\
\hline
\end{tabular}

Bolded numbers indicate the number of individuals for whom data were available (percentages exclude those for whom data were not reported)

a Reported for patients in whom treatment outcomes were reported. Successful treatment was defined as an outcome of either 'cured' or 'treatment completed'; Unsuccessful treatment was defined as 'treatment failure,' 'loss to follow-up', or 'death'. 24 patients from Hanoi and 26 patients from Thanh Hoa were lacking treatment outcomes

Patients with RR-/MDR-TB in this study were more likely to achieve treatment success in comparison to those with pre-XDR-TB and XDR-TB. This is consistent with global treatment success rates estimates of just $56 \%$ and 30\% for MDR-TB and XDR-TB patients, respectively $[12,16]$. As such, in cases where treatment failure results in additional acquired antibiotic resistance, a prolonged and more complicated retreatment may be required, further reducing the odds of a successful outcome. This is particularly problematic for patients with already substantial resistance as it limits future treatment options to less effective and potentially more toxic regimens. In addition, treatment failure may prolong the period in which the patient is infectious, thus potentially contributing to ongoing community transmission. Although acquired resistance was not specifically recorded in this study, $12 \%$ of patients reported considerable antibiotic resistance (pre-XDR-/XDR-TB) at diagnosis. Due to the poor treatment success rate and risks associated with higher levels of resistance, treatment of these patients represents a major clinical and public health challenge for Vietnam's healthcare system.

Patients in this study who attained culture conversion by the end of 4 months were considerably more likely to ultimately achieve treatment success compared to those whose sputum remained positive after 4 months. This highlights both the utility of routine and accurate testing, and the importance of bacteriological conversion early in treatment. While conversion after 2 months of treatment has been suggested as a possible means for predicting treatment success [17], the results of this study are consistent with evidence showing conversion results after
4 months to be a more useful indicator [18]. While both sputum smear and culture results were acceptable predictors of treatment success, we found culture results to be a more suitable option when adjusted for all variables included in the multivariable model.

The reduced odds of treatment success for males, compared to females, was consistent with studies showing poorer treatment outcomes amongst male patients treated for MDR-TB $[19,20]$. This may be a reflection of the higher risk of loss to follow-up among male patients, which in turn may be related to the financial burden associated with MDR-TB treatment. Catastrophic treatment-related costs borne by the household have been shown to be a significant barrier to treatment success $[5,21,22]$. In cases where male patients are the primary breadwinner, loss of employment or time away from work during treatment can result in considerable income reduction, placing financial strain on a patient's household. This in turn may prompt voluntary withdrawal from treatment in order to return to work, resulting in poorer treatment adherence amongst male patients. As such, financial support through the social health insurance (SHI) program may be an important protective measure against poor treatment outcomes. Although not significantly associated with treatment success, our study showed that patients receiving subsidies through the public social health insurance scheme experienced lower rates of loss to follow-up (see Additional file 1: Table S3), which is consistent with research in other settings $[5,6$, 23]. This highlights the importance of financial support for patients during treatment, especially if the patient is the primary breadwinner for their household. As such, 
Table 4 Univariate analyses of treatment variables for the outcome of treatment success versus treatment failure, loss to follow-up, or death, using complete case analysis

\begin{tabular}{|c|c|c|c|c|}
\hline \multirow[t]{2}{*}{ Variable } & \multicolumn{2}{|c|}{ Treatment outcome [n (\%)] } & \multirow{2}{*}{$\begin{array}{l}\text { Odds of treatment success } \\
\text { versus failure, loss to follow-up, } \\
\text { or death }[\mathrm{cOR}(95 \% \mathrm{CI})]\end{array}$} & \multirow[t]{2}{*}{$p$-value } \\
\hline & Success & $\begin{array}{l}\text { Failure, loss to follow-up, } \\
\text { or death }\end{array}$ & & \\
\hline Age $(n=612)$ & $n / a^{a}$ & $n / a^{a}$ & $0.99(0.97-1.00)$ & 0.013 \\
\hline \multicolumn{5}{|l|}{ Gender $(n=612)$} \\
\hline Female & $112(75.7 \%)$ & $36(24.3 \%)$ & 1.00 (reference) & 0.003 \\
\hline Male & $289(62.3 \%)$ & $175(37.7 \%)$ & $0.53(0.35-0.81)$ & \\
\hline \multicolumn{5}{|c|}{ Previous treatment $(n=594)$} \\
\hline No & $65(62.5 \%)$ & $39(37.5 \%)$ & 1.00 (reference) & 0.456 \\
\hline Yes & $325(66.3 \%)$ & $165(33.7 \%)$ & $1.18(0.76-1.83)$ & \\
\hline \multicolumn{5}{|c|}{ Financially supported through SHI $(n=426)$} \\
\hline No & $72(62.6 \%)$ & $43(37.4 \%)$ & 1.00 (reference) & 0.310 \\
\hline Yes & $211(67.8 \%)$ & $100(32.2 \%)$ & $1.26(0.81-1.97)$ & \\
\hline \multicolumn{5}{|l|}{ Diabetes $(n=424)$} \\
\hline No & $256(68.6 \%)$ & $117(31.4 \%)$ & 1.00 (reference) & 0.053 \\
\hline Yes & $28(54.9 \%)$ & $23(45.1 \%)$ & $0.56(0.31-1.01)$ & \\
\hline \multicolumn{5}{|c|}{ Heart disease $(n=424)$} \\
\hline No & $275(67.7 \%)$ & $131(32.3 \%)$ & 1.00 (reference) & 0.125 \\
\hline Yes & $9(50.0 \%)$ & $9(50.0 \%)$ & $0.48(0.19-1.23)$ & \\
\hline \multicolumn{5}{|l|}{ HIV $(n=500)$} \\
\hline No & $319(68.8 \%)$ & $145(31.2 \%)$ & 1.00 (reference) & 0.001 \\
\hline Yes & $15(41.7 \%)$ & $21(58.3 \%)$ & $0.33(0.16-0.65)$ & \\
\hline \multicolumn{5}{|c|}{ Kidney disease $(n=424)$} \\
\hline No & $283(67.1 \%)$ & $139(32.9 \%)$ & 1.00 (reference) & 0.616 \\
\hline Yes & $1(50.0 \%)$ & $1(50.0 \%)$ & $0.49(0.03-7.91)$ & \\
\hline \multicolumn{5}{|c|}{ Liver disease $(n=424)$} \\
\hline No & $273(67.6 \%)$ & $131(32.4 \%)$ & 1.00 (reference) & 0.248 \\
\hline Yes & $11(55.0 \%)$ & $9(45.0 \%)$ & $0.59(0.24-1.45)$ & \\
\hline \multicolumn{5}{|l|}{ Malnutrition $(n=424)$} \\
\hline No & $277(67.4 \%)$ & $134(32.6 \%)$ & 1.00 (reference) & 0.312 \\
\hline Yes & $7(53.8 \%)$ & $6(46.2 \%)$ & $0.46(0.19-1.71)$ & \\
\hline \multicolumn{5}{|c|}{ Psychiatric disorder $(n=424)$} \\
\hline No & $274(66.5 \%)$ & $138(33.5 \%)$ & 1.00 (reference) & 0.237 \\
\hline Yes & $10(83.3 \%)$ & $2(16.7 \%)$ & $2.52(0.54-11.65)$ & \\
\hline \multicolumn{5}{|c|}{ Respiratory disorder $^{b}(n=424)$} \\
\hline No & $256(68.8 \%)$ & $116(31.2 \%)$ & 1.00 (reference) & 0.034 \\
\hline Yes & $28(53.8 \%)$ & $24(46.2 \%)$ & $0.53(0.29-0.95)$ & \\
\hline \multicolumn{5}{|c|}{ Substance abuse $(n=424)$} \\
\hline No & $277(68.1 \%)$ & $130(31.9 \%)$ & 1.00 (reference) & 0.027 \\
\hline Yes & $7(41.2 \%)$ & $10(58.8 \%)$ & $0.33(0.12-0.88)$ & \\
\hline \multicolumn{5}{|c|}{ Other comorbidity ${ }^{c}(n=424)$} \\
\hline No & $277(67.4 \%)$ & $134(32.6 \%)$ & 1.00 (reference) & 0.312 \\
\hline Yes & $7(53.8 \%)$ & $6(46.2 \%)$ & $0.56(0.19-1.71)$ & \\
\hline \multicolumn{5}{|c|}{ Infection site $(n=598)$} \\
\hline Pulmonary & $378(65.4 \%)$ & $200(34.6 \%)$ & 1.00 (reference) & 0.777 \\
\hline Extrapulmonary & $9(75.0 \%)$ & $3(25.0 \%)$ & $1.59(0.43-5.92)$ & 0.492 \\
\hline Both & $5(62.5 \%)$ & $3(37.5 \%)$ & $0.88(0.21-3.72)$ & 0.864 \\
\hline
\end{tabular}


Table 4 (continued)

\begin{tabular}{|c|c|c|c|c|}
\hline \multirow[t]{2}{*}{ Variable } & \multicolumn{2}{|c|}{ Treatment outcome [n (\%)] } & \multirow{2}{*}{$\begin{array}{l}\text { Odds of treatment success } \\
\text { versus failure, loss to follow-up, } \\
\text { or death [cOR }(95 \% \mathrm{CI})]\end{array}$} & \multirow[t]{2}{*}{$p$-value } \\
\hline & Success & $\begin{array}{l}\text { Failure, loss to follow-up, } \\
\text { or death }\end{array}$ & & \\
\hline \multicolumn{5}{|c|}{ Antibiotic resistance $(n=409)$} \\
\hline RR-/MDR-TB & 255 (71.4\%) & $102(28.6 \%)$ & 1.00 (reference) & \multirow[t]{2}{*}{0.000} \\
\hline Pre-XDR or XDR-TB & $24(47.2 \%)$ & $28(52.8 \%)$ & $0.34(0.19-0.62)$ & \\
\hline \multicolumn{5}{|c|}{ Initial sputum (smear) positivity $(n=584)$} \\
\hline No & $149(69.6 \%)$ & $65(30.4 \%)$ & 1.00 (reference) & \multirow[t]{2}{*}{0.152} \\
\hline Yes & $235(63.7 \%)$ & $134(36.3 \%)$ & $0.77(0.54-1.10)$ & \\
\hline \multicolumn{5}{|c|}{ Smear conversion after 2 months $(n=557)$} \\
\hline No & $41(53.2 \%)$ & $36(46.8 \%)$ & 1.00 (reference) & \multirow[t]{2}{*}{0.002} \\
\hline Yes & 341 (71.0\%) & $139(29.0 \%)$ & $2.15(1.32-3.51)$ & \\
\hline \multicolumn{5}{|c|}{ Culture conversion after 2 months $(n=526)$} \\
\hline No & $75(62.5 \%)$ & $45(37.5 \%)$ & 1.00 (reference) & \multirow[t]{2}{*}{0.071} \\
\hline Yes & $289(71.2 \%)$ & $117(28.8 \%)$ & $1.48(0.97-2.27)$ & \\
\hline \multicolumn{5}{|c|}{ Smear conversion after 4 months $(n=518)$} \\
\hline No & $6(37.5 \%)$ & $10(62.5 \%)$ & 1.00 (reference) & \multirow[t]{2}{*}{0.005} \\
\hline Yes & $364(72.5 \%)$ & $138(27.5 \%)$ & $4.40(1.57-12.33)$ & \\
\hline \multicolumn{5}{|c|}{ Culture conversion after 4 months $(n=509)$} \\
\hline No & $15(44.1 \%)$ & $19(55.9 \%)$ & 1.00 (reference) & \multirow[t]{2}{*}{0.000} \\
\hline Yes & $351(73.9 \%)$ & $124(26.1 \%)$ & $3.59(1.77-7.27)$ & \\
\hline \multicolumn{5}{|c|}{ At least one side effect experienced during inpatient treatment $(n=418)$} \\
\hline No & $261(67.4 \%)$ & $126(32.6 \%)$ & 1.00 (reference) & \multirow[t]{2}{*}{0.077} \\
\hline Yes & $16(51.6 \%)$ & $15(48.4 \%)$ & $0.52(0.25-1.08)$ & \\
\hline \multicolumn{5}{|c|}{ At least one side effect experienced during outpatient treatment $(n=545)$} \\
\hline No & $294(66.2 \%)$ & $150(33.8 \%)$ & 1.00 (reference) & \multirow[t]{2}{*}{0.120} \\
\hline Yes & 75 (74.3\%) & $26(25.7 \%)$ & $1.47(0.90-2.40)$ & \\
\hline
\end{tabular}

$\mathrm{COR}=$ crude (unadjusted) odds ratio

$\mathrm{n}=$ number of individuals for whom data were available

RR-/MDR-TB = rifampicin-resistant or multidrug-resistant tuberculosis

Pre-XDR or XDR-TB = pre-extensively drug resistant tuberculosis or extensively drug resistant tuberculosis

Bolded variables were included in the multivariable analysis

${ }^{\text {a }}$ Age is represented as a continuous variable in the model

${ }^{b}$ Respiratory disorder refers to either: atelectasis, bronchiectasis, bronchitis, bronchopneumonia, chronic pulmonary disease, lung tumor, pneumonia, pneumothorax, or respiratory failure

' Other includes: adrenal failure, anaemia, esophageal cancer, gout, pleural effusion, and a seizure disorder

this support should include not only direct costs (e.g., medication and transportation), but also indirect costs, such as loss of wages, to compensate for the reduction of household income. This could have an effect on the overall treatment success rate by offering an incentive with which to complete treatment, thus improving patient retention.

This study has a number of limitations. As we relied upon routinely collected programmatic data, a proportion of cases lacked complete data, particularly for comorbidities and treatment toxicity results. Furthermore, screening for treatment toxicity was not standardised. This may have resulted in ascertainment bias, and an underestimation of the frequency of adverse events and their effect upon treatment outcomes. In addition, missing outcome data may have resulted in either an underestimation or overestimation of the overall treatment success rate. Although the characteristics of patients for whom a treatment outcome was unavailable were otherwise similar to that of patients with a reported treatment outcome (see Additional file 1: Tables S6 and S7), it is unclear as to how many of these patients may have achieved treatment success. A lack of complete case data also presented challenges in performing the multivariable analysis. As multiple imputation was used to complete the dataset used in the multivariable analysis, a level of 
Table 5 Multivariable analysis of treatment variables for the outcome of treatment success versus treatment failure, loss to follow-up, or death

\begin{tabular}{|c|c|c|c|c|}
\hline \multirow[t]{2}{*}{ Variable } & \multicolumn{2}{|c|}{ Treatment outcome [n (\%)] } & \multirow{2}{*}{$\begin{array}{l}\text { Odds of treatment success versus failure, loss to } \\
\text { follow-up, or death [aOR }(95 \% \mathrm{Cl})]\end{array}$} & \multirow[t]{2}{*}{$p$-value } \\
\hline & Success $(n=401)$ & $\begin{array}{l}\text { Failure, loss to follow-up, or } \\
\text { death }(n=211)\end{array}$ & & \\
\hline Age & $\mathrm{n} / \mathrm{a}^{\mathrm{a}}$ & $\mathrm{n} / \mathrm{a}^{\mathrm{a}}$ & $0.99(0.98-1.00)$ & 0.079 \\
\hline \multicolumn{5}{|l|}{ Gender } \\
\hline Female & $112(75.7 \%)$ & $36(24.3 \%)$ & 1.00 (reference) & \multirow[t]{2}{*}{0.016} \\
\hline Male & $289(62.3 \%)$ & 175 (37.7\%) & $0.56(0.34-0.90)$ & \\
\hline \multicolumn{5}{|l|}{ Diabetes } \\
\hline No & $315(67.5 \%)$ & $152(32.5 \%)$ & 1.00 (reference) & \multirow[t]{2}{*}{0.286} \\
\hline Yes & $86(59.3 \%)$ & $59(40.7 \%)$ & $0.72(0.40-1.32)$ & \\
\hline \multicolumn{5}{|l|}{ Heart disease } \\
\hline No & $339(66.7 \%)$ & $169(33.3 \%)$ & 1.00 (reference) & \multirow[t]{2}{*}{0.683} \\
\hline Yes & $62(59.6 \%)$ & $42(40.4 \%)$ & $0.83(0.33-2.05)$ & \\
\hline \multicolumn{5}{|l|}{ HIV } \\
\hline No & $377(67.0 \%)$ & $183(33.0 \%)$ & 1.00 (reference) & \multirow[t]{2}{*}{0.049} \\
\hline Yes & $24(46.2 \%)$ & $28(53.8 \%)$ & $0.44(0.20-1.00)$ & \\
\hline \multicolumn{5}{|l|}{ Respiratory disorder ${ }^{b}$} \\
\hline No & $337(67.0 \%)$ & $166(33.0 \%)$ & 1.00 (reference) & \multirow[t]{2}{*}{0.395} \\
\hline Yes & $64(58.7 \%)$ & $45(41.3 \%)$ & $0.76(0.41-1.42)$ & \\
\hline \multicolumn{5}{|l|}{ Substance abuse } \\
\hline No & $339(66.9 \%)$ & $168(33.1 \%)$ & 1.00 (reference) & \multirow[t]{2}{*}{0.607} \\
\hline Yes & $62(59.0 \%)$ & $43(41.0 \%)$ & $0.77(0.29-2.09)$ & \\
\hline \multicolumn{5}{|l|}{ Antibiotic resistance } \\
\hline RR/MDR-TB' & $331(68.0 \%)$ & $156(32.0 \%)$ & 1.00 (reference) & \multirow[t]{2}{*}{0.039} \\
\hline Pre-XDR or XDR-TB ${ }^{d}$ & $70(56.0 \%)$ & $55(44.0 \%)$ & $0.53(0.29-0.97)$ & \\
\hline \multicolumn{5}{|c|}{ Initial sputum (smear) positivity } \\
\hline No & $155(69.2 \%)$ & $69(30.8 \%)$ & 1.00 (reference) & \multirow[t]{2}{*}{0.429} \\
\hline Yes & $246(63.4 \%)$ & $142(36.6 \%)$ & $0.85(0.57-1.27)$ & \\
\hline \multicolumn{5}{|c|}{ Smear conversion after 2 months } \\
\hline No & $45(50.0 \%)$ & $45(50.0 \%)$ & 1.00 (reference) & \multirow[t]{2}{*}{0.204} \\
\hline Yes & $356(68.2 \%)$ & $166(31.8 \%)$ & $1.47(0.81-2.67)$ & \\
\hline \multicolumn{5}{|c|}{ Culture conversion after 2 months } \\
\hline No & $85(58.2 \%)$ & $61(41.8 \%)$ & 1.00 (reference) & \multirow[t]{2}{*}{0.361} \\
\hline Yes & $316(67.8 \%)$ & $150(32.2 \%)$ & $1.28(0.75-2.20)$ & \\
\hline Smear conversion after 4 & & & & \\
\hline No & $12(34.2 \%)$ & $23(65.8 \%)$ & 1.00 (reference) & 0.106 \\
\hline Yes & $389(67.4 \%)$ & $188(32.6 \%)$ & $2.47(0.82-7.39)$ & \\
\hline Culture conversion afte & onths & & & \\
\hline No & $22(42.3 \%)$ & $30(57.7 \%)$ & 1.00 (reference) & 0.008 \\
\hline Yes & $379(67.7 \%)$ & $181(32.3 \%)$ & $2.93(1.33-6.45)$ & \\
\hline At least one side effect ex & ced during inpatient & & & \\
\hline No & $336(66.8 \%)$ & $167(33.2 \%)$ & 1.00 (reference) & 0.645 \\
\hline Yes & $65(59.6 \%)$ & $44(40.4 \%)$ & $0.80(0.32-2.05)$ & \\
\hline At least one side effect ex & ced during outpatier & nent & & \\
\hline No & $319(64.2 \%)$ & $178(35.8 \%)$ & 1.00 (reference) & 0.104 \\
\hline Yes & $82(71.3 \%)$ & $33(28.7 \%)$ & $1.54(0.91-2.61)$ & \\
\hline
\end{tabular}

Bolded variables were significantly $(p \leq 0.05)$ associated with the outcome

${ }^{a}$ Age is represented as a continuous variable in the model

${ }^{b}$ Respiratory disorder refers to either: atelectasis, bronchiectasis, bronchitis, bronchopneumonia, chronic pulmonary disease, lung tumor, pneumonia, pneumothorax, or respiratory failure

' Rifampicin-resistant or multidrug-resistant tuberculosis

${ }^{d}$ Pre-extensively-resistant or extensively-resistant tuberculosis 
uncertainty with the parameter estimates was unavoidable. However, while 20 imputations are considered sufficient to produce accurate estimates [24], 50 imputations were used in this study to ensure accuracy and preserve statistical testing power. Finally, the findings of this study are applicable to patients treated with regimens that accorded with WHO guidelines at the time. These results are not generalisable to patients treated with newer alloral regimens.

This study has important policy implications for the treatment of MDR-TB patients in Vietnam. We found that a high proportion $(34.5 \%)$ of patients did not achieve a successful treatment outcome. This indicates a significant gap between treatment policy and implementation. Unfortunately, the proportion of patients with successful treatment was lower than for the first cohort of patients with MDR-TB treated in Vietnam a decade ago. This may reflect the challenges in scaling-up care for MDR-TB, as well as regional differences in care. Additional interventions are required to retain patients in care, improve reporting of treatment toxicity, and optimize management of co-morbidities. A comprehensive standardized evaluation of co-morbidities at the time of enrolment in treatment may enable clinicians to provide holistic medical care and improve treatment outcomes. In addition, this study provides evidence to expand access to subsidised treatment for all patients, suggesting that further research is required to assess the effects of social health insurance coverage upon loss to follow-up during treatment. Financial support provided through insurance may have an important role in minimizing loss to follow-up, and including as many facets of the treatment process as possible in this scheme may have a beneficial impact on overall treatment adherence.

As advanced drug resistance significantly reduces the odd of success treatment outcome, pre-XDR-/XDR-TB patients should be carefully monitored to ensure treatment adherence, particularly during outpatient care. Drug susceptibility testing for second-line antibiotics should be used to individualise treatment in order to ensure optimal treatment outcomes and avoid acquired antibiotic resistance.

\section{Conclusions}

This study found that among patients with MDR-TB, males, people living with HIV, and those with more extensive antibiotic resistance at diagnosis are at greatest risk of an unsuccessful treatment outcome. Efforts to optimise the management of co-morbidities (such as HIV), ensure rapid bacteriological conversion, and provide financial support for patients promise to improve treatment outcomes and may contribute to a reduction in the risk of community transmission of MDR-TB.

\begin{abstract}
Abbreviations
aOR: Adjusted odds ratio; cOR: Crude (unadjusted) odds ratio; DST: Drug susceptibility testing; HIV: Human immunodeficiency virus; HREC: Human Research Ethics Committee; MDR-TB: Multidrug-resistant tuberculosis; NTP: National tuberculosis programme; PMDT: Programmatic management of drug-resistant tuberculosis; Pre-XDR-TB: Pre-extensively drug-resistant tuberculosis; RR-TB: Rifampicin-resistant tuberculosis; SHI: Social health insurance; TB: Tuberculosis; RR-TB: Rifampicin-resistant tuberculosis; WHO: World Health Organization; XDR-TB: Extensively drug-resistant tuberculosis.
\end{abstract}

\section{Supplementary Information}

The online version contains supplementary material available at https://doi. org/10.1186/s12879-021-06992-x.

Additional file 1. Supplementary figures and tables.

Additional file 2. Case report form template used for patient data collection.

Additional file 3. Multiple imputation parameters and results.

\section{Acknowledgements}

We thank the dedicated staff of the Woolcock Institute of Medical Research in Vietnam for their support and advice; the staff of the Vietnam Ministry of Health in Hanoi and Thanh Hoa provinces for their assistance in accessing the data presented here; and the Sydney Informatics Hub at the University of Sydney for technical support.

\section{Authors' contributions}

IW developed the study design, facilitated the collection of data, processed and analyzed data, and contributed to the production and revision of the manuscript. TA developed the study design, facilitated the collection and interpretation of data, and contributed to the production and revision of the manuscript. VN developed the study design, facilitated the acquisition of data, and contributed to the revision of the manuscript. BN developed the study design, interpreted study data, and contributed to the revision of the manuscript. TH developed the study design and contributed to the revision of the manuscript. PN developed the study design, collected and processed data, and contributed to the production and revision of the manuscript. KV developed the study design, analyzed and interpreted data, and contributed to the production and revision of the manuscript. GM developed the study design and contributed to the revision of the manuscript. GF developed the study design, analyzed and interpreted data, and contributed to the production and revision of the manuscript. All authors read and approved the final manuscript.

\section{Funding}

This project was supported by the University of Sydney, Australia. Greg J Fox was supported by a NHMRC Career Development Fellowship [Grant number APP1148372].

Availability of data and materials

The datasets used and/or analyzed during the current study are available from the corresponding author on reasonable request.

\section{Declarations}

\section{Ethics approval and consent to participate}

Ethical approval for the project was obtained though the Human Research Ethics Committee in at the University of Sydney in Australia (project no. 2018/746), and the Vietnam National Lung Hospital. All patient information was stored in a secure database during data collection and de-identified prior to analysis to ensure the confidentiality of study participants. 


\section{Consent for publication}

Not applicable.

\section{Competing interests}

The authors declare that they have no competing interests.

\section{Author details}

${ }^{1}$ The Central Clinical School, Faculty of Medicine and Health, The University of Sydney, 90-92 Parramatta Road, Sydney, NSW 2006, Australia. ${ }^{2}$ The Woolcock Institute of Medical Research, Sydney, NSW 2037, Australia. ${ }^{3}$ The Woolcock Institute of Medical Research, Hanoi, Vietnam. ${ }^{4}$ National Lung Hospital, Hanoi, Vietnam. ${ }^{5}$ South Western Sydney Clinical School, University of New South Wales, Sydney, NSW 2052, Australia.

Received: 2 March 2021 Accepted: 15 December 2021

Published online: 20 January 2022

\section{References}

1. WHO. Global Tuberculosis Report 2020. Geneva: World Health Organization; 2020.

2. Wu S, Zhang Y, Sun F, Chen M, Zhou L, Wang N, et al. Adverse events associated with the treatment of multidrug-resistant tuberculosis: a systematic review and meta-analysis. Am J Ther. 2016;23(2):e521-30.

3. WHO. Implementing the end TB strategy: the essentials. Geneva: World Health Organization; 2015

4. Vietnam National Tuberculosis Control Programme. Guidelines for the management and treatment of MDR-TB. Hanoi: Vietnam NTP; 2009.

5. Nhung NV, Hoa NB, Anh NT, Anh LTN, Siroka A, Lonnroth K, et al. Measuring catastrophic costs due to tuberculosis in Viet Nam. Int J Tuberc Lung Dis. 2018;22(9):983-90.

6. Ahmad N, Ahuja SD, Akkerman OW, Alffenaar J-WC, Anderson LF, Baghaei $P$, et al. Treatment correlates of successful outcomes in pulmonary multidrug-resistant tuberculosis: an individual patient data meta-analysis. The Lancet. 2018;392(10150):821-34.

7. WHO. Companion handbook to the WHO guidelines for the programmatic management of drug-resistant tuberculosis. Geneva: World Health Organisation; 2014.

8. Phuong NT, Nhung NV, Hoa NB, Thuy HT, Takarinda KC, Tayler-Smith K, et al. Management and treatment outcomes of patients enrolled in MDRTB treatment in Viet Nam. Public Health Action. 2016;6(1):25-31.

9. Van LH, Phu PT, Vinh DN, Son VT, Hanh NT, Nhat LTH, et al. Risk factors for poor treatment outcomes of 2266 multidrug-resistant tuberculosis cases in Ho Chi Minh City: a retrospective study. BMC Infect Dis. 2020;20(1):164.

10. Samuels JP, Sood A, Campbell JR, Ahmad Khan F, Johnston JC. Comorbidities and treatment outcomes in multidrug resistant tuberculosis: a systematic review and meta-analysis. Sci Rep. 2018;8(1):4980.

11. Trinh QM, Nguyen HL, Do TN, Nguyen VN, Nguyen BH, Nguyen TV, et al. Tuberculosis and HIV co-infection in Vietnam. Int J Infect Dis. 2016;46:56-60.

12. WHO. Global Tuberculosis Report 2017. Geneva: World Health Organization; 2017.

13. WHO. Joint review of the health sector response to HIV in Viet Nam 2014. Geneva: World Health Organization; 2014.

14. Courtwright A, Turner AN. Tuberculosis and stigmatization: pathways and interventions. Public Health Rep. 2010;125(Suppl 4):34-42.

15. Widjanarko BGM, Dijkers M, van der Werf MJ. Factors that influence treatment adherence of tuberculosis patients living in Java, Indonesia. Patient Prefer Adherence. 2009;3:231-8.

16. Falzon D, Gandhi N, Migliori GB, Sotgiu G, Cox HS, Holtz TH, et al. Resistance to fluoroquinolones and second-line injectable drugs: impact on multidrug-resistant TB outcomes. Eur Respir J. 2013;42(1):156-68.

17. Lv L, Li T, Xu K, Shi P, He B, Kong W, et al. Sputum bacteriology conversion and treatment outcome of patients with multidrug-resistant tuberculosis. Infect Drug Resistance. 2018;11:147-54.

18. Alene KA, Viney K, Yi H, McBryde ES, Yang K, Bai L, et al. Comparison of the validity of smear and culture conversion as a prognostic marker of treatment outcome in patients with multidrug-resistant tuberculosis. PLoS One. 2018;13(5):e0197880.
19. Feng JY, Huang SF, Ting WY, Chen YC, Lin YY, Huang RM, et al. Gender differences in treatment outcomes of tuberculosis patients in Taiwan: a prospective observational study. Clin Microbiol Infect. 2012;18(9):E331-7.

20. Johnston JC, Shahidi NC, Sadatsafavi M, Fitzgerald JM. Treatment outcomes of multidrug-resistant tuberculosis: a systematic review and meta-analysis. PLoS ONE. 2009;4(9):e6914.

21. Nam VX, Nhung NV, Hoa NB, Thuy HTT, Phuong NTM, Anh NT, et al. Economic burden of multidrug-resistant tuberculosis: a multicenter study across Vietnamese regions. Int J Tuberc Lung Dis. 2018;22(8):912-7.

22. Tola HH, Tol A, Shojaeizadeh D, Garmaroudi G. Tuberculosis treatment non-adherence and lost to follow up among TB patients with or without HIV in developing countries: a systematic review. Iran J Public Health. 2015:4(1):1-11.

23. Bagchi S, Ambe G, Sathiakumar N. Determinants of poor adherence to anti-tuberculosis treatment in Mumbai, India. Int J Prev Med. 2010;1(4):223-32.

24. Graham JW, Olchowski AE, Gilreath TD. How many imputations are really needed? Some practical clarifications of multiple imputation theory. Prev Sci. 2007;8(3):206-13.

\section{Publisher's Note}

Springer Nature remains neutral with regard to jurisdictional claims in published maps and institutional affiliations.

Ready to submit your research? Choose BMC and benefit from:

- fast, convenient online submission

- thorough peer review by experienced researchers in your field

- rapid publication on acceptance

- support for research data, including large and complex data types

- gold Open Access which fosters wider collaboration and increased citations

- maximum visibility for your research: over 100M website views per year

At BMC, research is always in progress.

Learn more biomedcentral.com/submissions 